\title{
Modeling Social Impacts of High-Rise Residential Buildings during the Post-Occupancy Phase Using DEMATEL Method: A Case Study
}

\author{
Ngakan Ketut Acwin Dwijendra ${ }^{1}$, Ravil Akhmadeev ${ }^{2}$, Dmitry Tumanov ${ }^{3}$, Mikhail Kosov ${ }^{2,4}$, Shahab Shoar ${ }^{5, *(D)}$ \\ and Audrius Banaitis $6, *$ (D) \\ 1 Department of Architecture, Faculty of Engineering, Udayana University, Bali 80361, Indonesia; \\ acwin@unud.ac.id \\ 2 Department of Finance and Prices, Plekhanov Russian University of Economics, Stremyanny Lane, 36, \\ 117997 Moscow, Russia; Ahm_rav@mail.ru (R.A.); Kosovme@mail.ru (M.K.) \\ 3 Department of Legal and Social Sciences, Kazan Federal University-Naberezhnye Chelny Institute, \\ 423812 Tatarstan, Russia; dmitriy-tumanov8975905@mail.ru \\ 4 National Research University Higher School of Economics, 11 Pokrovsky Bulvar, 109028 Moscow, Russia \\ 5 Department of Project and Construction Management, Mehralborz Institute of Higher Education, \\ Tehran 141368449, Iran \\ 6 Department of Construction Management and Real Estate, Vilnius Gediminas Technical University, \\ Sauletekio al. 11, 10223 Vilnius, Lithuania \\ * Correspondence: shahab.shoar@yahoo.com (S.S.); audrius.banaitis@vilniustech.lt (A.B.)
}

Citation: Dwijendra, N.K.A.; Akhmadeev, R.; Tumanov, D.; Kosov, M.; Shoar, S.; Banaitis, A. Modeling Social Impacts of High-Rise Residential Buildings during the Post-Occupancy Phase Using DEMATEL Method: A Case Study. Buildings 2021, 11, 504. https:// doi.org/10.3390/buildings11110504

Academic Editors: Chyi Lin Lee, Samad M. E. Sepasgozar and Lan Ding

Received: 3 October 2021

Accepted: 19 October 2021

Published: 25 October 202

Publisher's Note: MDPI stays neutral with regard to jurisdictional claims in published maps and institutional affiliations.

Copyright: (c) 2021 by the authors Licensee MDPI, Basel, Switzerland. This article is an open access article distributed under the terms and conditions of the Creative Commons Attribution (CC BY) license (https:// creativecommons.org/licenses/by/ $4.0 /)$
Abstract: There are numerous risks associated with high-rise buildings, which not only affect stakeholders during the design and construction phase but also impact the occupants and the surrounding environment during the post-occupancy phase. While previous studies examined the risks of high-rise building construction, less attention has been paid to the diverse impacts of high-rise buildings on their occupants. To fill this gap, this study applied a mixed-method approach (both quantitative and qualitative) to identify and prioritize their most significant social impacts. First, the possible social impacts of these buildings were identified via a literature review. The interrelationships among the identified factors were then determined by drawing on the opinions of relevant experts. Next, through the quantitative phase, the high-rise residential buildings of District 22 of Tehran were considered as a case study, and according to the opinions of 230 chosen residents, the level of influence of factors on one another was determined. The DEMATEL approach was employed subsequently to analyze the data and identify the most important and influential factors. Finally, through the qualitative phase, in-depth interviews were conducted with residents to explain and validate the results. The most significant and influential impacts identified by this study were anti-social behavior, lack of social cohesion, and lack of social contact with neighbors. This study assists designers and policymakers to adopt strategies that could mitigate the identified impacts and improve occupants' social wellbeing more efficiently.

Keywords: high-rise building; social interaction; anti-social behavior; social cohesion; occupants' social wellbeing; DEMATEL method

\section{Introduction}

It is believed that the construction industry significantly contributes to the economy of both developed and developing countries [1-3]. Within the urban contexts, this industry especially lends its prosperity to high-rise buildings, among other project types, as they absorb considerable investments from both public and private sectors and play a crucial role in the development of a country [4]. There is not an absolute definition of a highrise building. Some definitions and codes merely considered height as the main aspect. Farouk [5], for example, considered a high-rise building as one whose total height exceeds 
$36 \mathrm{~m}$. Based on Russian building codes, buildings rising between 75 and $150 \mathrm{~m}$ are classified as high-rise buildings [6]. On the contrary, some others paid more attention to the surrounding environment. Kloft [7], for example, opined that a high-rise building is one that is considerably higher than surrounding buildings. Similarly, Urban Strategies [8] defined high-rise buildings as ones with a height that is greater than the width of the adjacent street right-of-way or the wider of two streets if located at an intersection. Apart from available definitions, what is worth considering is that there has recently been a growing trend to erect more high-rise residential buildings, notably across megacities, around the world. Perera et al. [9], for instance, reported that many high-rise luxury projects have been erected in Sri Lanka during the last decades, and many of them will be completed in the not-too-distant future. A similar trend has been witnessed in other countries such as Hong Kong [10], Russia [6], and the UK [11]. The rapid growth of the population is certainly a reasonable explanation for this trend. Today, cities accommodate more than half of the world's population, and this figure is predicted to be on the rise [12]. Therefore, there is not enough vacant land for building construction, and as a result, the land price has unprecedently increased, especially within urban areas [6]. These have prompted developers to turn to high-rise buildings to provide more accommodation for people. Another reason for this trend is indeed the prestige that these buildings bestow upon cities. That is to say, high-rise buildings are representative of recent advances in architecture and technology, and the erection of a building that surpasses the height of buildings in other regions can provide dignity for a city or even a country. That is why more and more town planners and city authorities these days are willing to build something that attracts attention. Overall, it can be concluded that the demand for erecting high-rise buildings lies in not only social and technical needs but also in symbolism, ego, and showcasing the industrial and technological development to gain wealth and create growth [13,14].

Having perceived the significance of these projects, numerous researchers have focused on identifying and analyzing risks that affect high-rise building projects' success. Santoso et al. [15], for example, identified and categorized critical risks in high-rise building projects in Jakarta and argued that risks associated with management and design are the most important ones. In the same vein, Perera et al. [9] identified the financial/economic risk factors of high-rise apartment building projects and their risk response measures in Sri Lanka and concluded that financial problems arising from errors in estimating and poor contract management are the major risk factors. However, high-rise buildings could have diverse negative impacts on their occupants, which is worth considering. Alexander et al. [16], for instance, argued that tall buildings make people crazy. In other words, buildings can potentially affect occupants' health, wellbeing, productivity, and social connection, and thereby surveying occupants' opinions about whether or not the indoor environment supports the activities performed is imperative. However, most postoccupancy evaluations have concentrated mainly on measuring residents' levels of comfort and environmental satisfaction, and adequate attention has not been paid to their social wellbeing [17]. It is worth mentioning that social interactions, both in terms of quality and quantity, can have a short- and long-term influence on occupants' mental wellbeing and physical health [18]. Several studies have been carried out to identify the everyday human effects of high-rise living and working [19]. However, a large proportion of these studies targeted developed countries of North America, Europe, and East Asia, and there is no evidence for developing countries [19]. Apart from this, there are no studies that scrutinize the interrelationships among the impacts, notably social ones. As argued by Barros et al. [20], considering these relations is essential as they can advance our knowledge of the potential roles of urban design and architectural solutions on enhancing the social wellbeing of those living in high-rise residential buildings.

To fill this gap, the aim of this research is to examine and prioritize the social effects of high-rise buildings on their residents. Overall, this study seeks to find answers to the following questions. 
1. How are various impacts arising from living in high-rise residential buildings connected and how do they influence each other?

2. What factors act as the main root causes of the problem under consideration?

3. What factors act as the main effects of the problem under consideration?

4. What are the most important aspects that designers and policymakers should focus on to mitigate social impacts?

The case study region is District 22 of Tehran, Iran, which is located in the northwest part of the city. This region was chosen as based on the Statistics and Informatics Report of the Planning Department of Tehran Municipality Office, the construction trend of highrise buildings in District 22 increased by 103\% over the years 2004-2014 [21]. It is also worthwhile to mention that $2.02 \%$ of the population of Tehran resides in this district, and it includes 125 high-rise residential buildings with more than 10 stories [22]. Social impacts of high-rise buildings were identified through a literature review and validated by interviewing a panel of relevant experts. By drawing on the opinions of 230 residents and using the Decision-Making Trial and Evaluation Laboratory (DEMATEL) method, the identified impacts were then ranked. Interviews with seven residents were also conducted to further discuss the results. The findings of this study are expected to assist designers to gain better insight into the most severe impacts and aid them with adopting proportional strategies to mitigate the effects and improve occupants' social wellbeing.

The remainder of this study is organized as follows. The next section conducted a literature review to identify the diverse social effects of high-rise buildings. In the third section, the research methods, including the research process, data collection, and data analysis are discussed. Next, results and discussions sections are presented in which the main effects are identified and discussed. Finally, the last section summarizes the conclusions of the study and sheds light on the limitations and suggestions for future research.

\section{Literature Review}

During recent decades, several studies have been carried out to investigate the impact of specific types of high-rise buildings, and residential buildings, among others, have received utmost attention. This should not come as a surprise considering the global trajectory of rural-to-urban migration and the booming construction industry for urban residences [23]. Various categories have been suggested for the impacts of high-rise buildings. Kearns et al. [11], for example, categorized detrimental effects of high-rise living into five categories including crime and informal social control, mental health effects, social effects, impacts on families and children, and physical health effects. Kalantari and Shepley [19] considered four categories for the effects of high-rise residential buildings. These groups were social interaction, mental health, safety and crime, and the experiences of specific population groups. It should be noted that these buildings can also pose serious problems for the people living in their vicinity. For instance, they might violate the rights of others in the neighborhood for natural light and visual quality [24]. In the same vein, high-rise buildings, if located inappropriately, can lead to increased traffic volumes, traffic noise pollution, air pollution, and also put more pressure on the transport networks [25]. These could all result in adverse effects on public health and wellbeing [26]. Therefore, other categories such as environmental impacts and city structure impacts could also be considered. However, as this study concentrated on occupants, these groups are excluded. In this research, only the social impacts of high-rise living are considered, and the factors that it includes are delineated below.

\subsection{High-Rise Buildings' Social Impacts}

Numerous studies have been conducted on the social impacts of high-rise buildings, and they identified social variables such as social contact with family and friends, social contact with neighbors, anti-social behavior, social support, social cohesion, sense of belonging, sense of community, social development of children, and safety. With regard to social contacts, Chile et al. [27], for example, argued that a low level of social contact with 
other members of a community is the key factor leading to social isolation for inner-city high-rise apartment occupants. Similarly, Chatterjee [28] compared two groups of residents in high-rise buildings and non-high-rise buildings in Kolkata, India, and concluded that the high-rise occupants expressed greater feelings of social negativity and loneliness. Taking anti-social behavior and sense of community into account, Kearns et al. [11] compared the impacts of living in a high-rise with other dwelling types in the deprived areas of Glasgow and revealed that high-rise occupants had a weaker sense of community and a higher incidence of serious anti-social behavior and lower levels of trust in their neighbors. These variables were also targeted and identified in other studies such as [29] and [30], which examined the deprived context of the UK and Canada, respectively. Considering social support, Husaini et al. [31] compared black elderly living in senior high-rise apartments with those living in community housing and concluded that the high-rise group was subject to less social support, poorer health, more stress, and higher levels of depression. This factor was also highlighted by Korte and Huismans [32], who studied Dutch high-rise buildings. Concerning the sense of belonging, Kearns et al. [33] asserted that this variable is associated with the mental health and well-being of residents. In the same vein, Kitchen et al. [34], who investigated the sense of belonging among settlements of different sizes in Canada, concluded that the sense of belonging was lowest among youth, residents of high-rise apartments, and single-parents. With regard to the social development of children, Saegart [35] asserted that children of low-income families residing in crowding high-rise apartments show more psychological distress and have more behavioral and learning difficulties than other children residing in low-rise apartments or houses. Finally, concerning safety, Kearns et al. [11] reported that young children's parents in high-rise buildings kept their children indoors more than other parents, because of safety concerns and difficulties of supervision at a distance. This variable was also highlighted in Gibson et al.'s [29] study, and they argued that the feeling of safety was higher among residents of houses compared to that of high-rise apartments.

\subsection{Research Gap}

Overall, it can be concluded that high-rise living environments can give rise to social isolation, social annoyance, and anonymity for their residents. While previous studies investigated the magnitude of these variables' impact within various contexts (i.e., deprived and privileged) and delved into their relations with other parameters such as mental health and personal characteristics, research on the interactions of these social variables in high-rise living environments is still scarce and requires more empirical evidence. It is believed that identifying the most significant and influential variables provides a better understanding for planners and designers on how to design tall buildings and enhance the quality of living in high-rise apartment buildings in order to support social interaction and sustainable living. All the factors identified through this section are represented in Figure 1. 


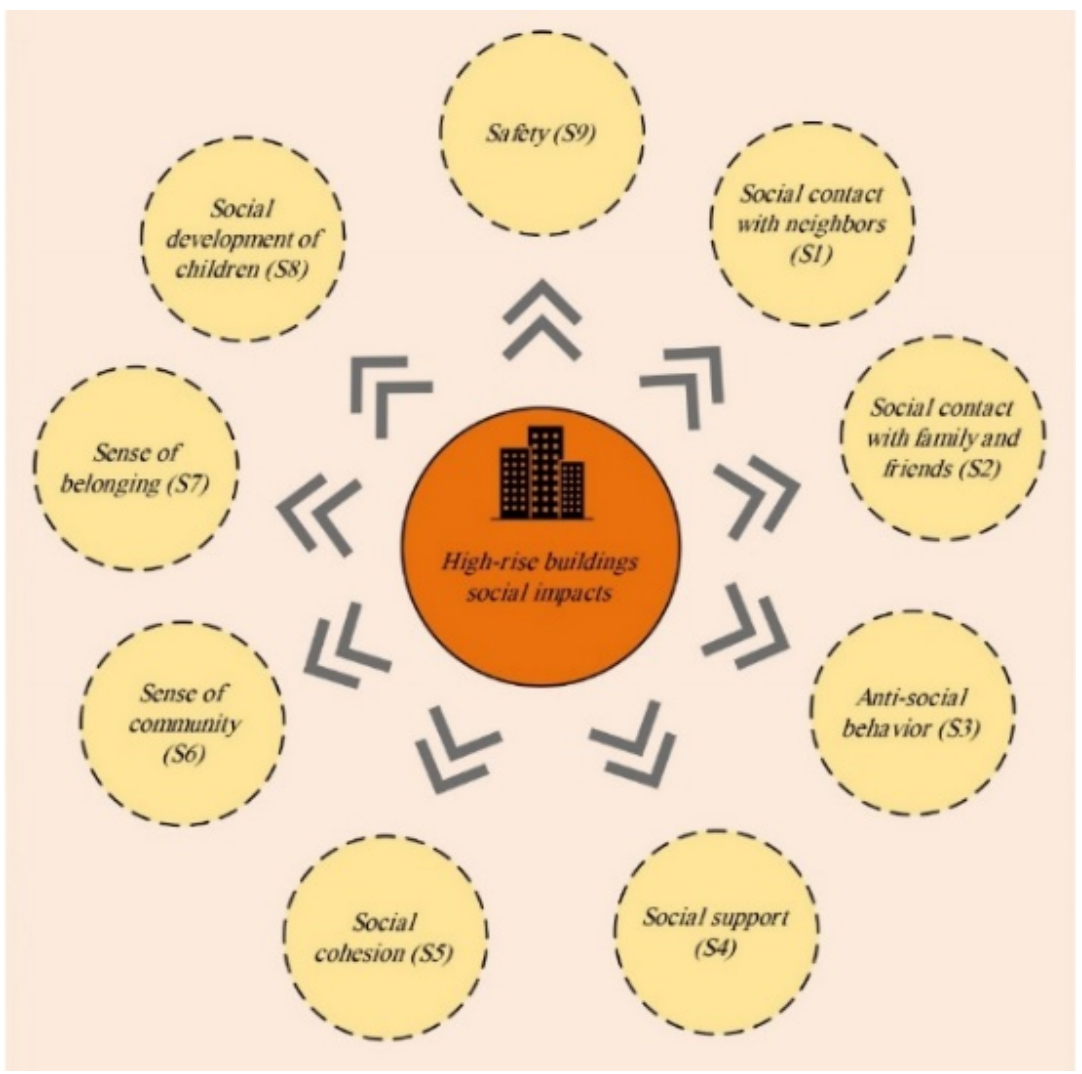

Figure 1. High-rise residential buildings' social impacts.

\section{Research Methods}

A mixed-method approach (both quantitative and qualitative) was employed in this research. Five primary designs can be adopted using the mixed-methods approach depending on the research questions posed and resources available for the evaluation [36]. This study adopted a design that uses qualitative data to explore the quantitative findings. It is believed that using different methods to investigate a single problem can improve the accuracy and validity of the results [37]. This approach has also been adopted by previous studies in the same domain. Li [38], for example, utilized a combination of in-depth interviews and questionnaire surveys to investigate factors affecting home-purchase decisions of two different generations. Likewise, Nguyen et al. [39] adopted a mixed-method approach to examine how often and where people in high-rise neighborhoods interact.

As illustrated in Figure 2, the research process of this study is organized in four stages as follows.

In the first stage, through a literature review, which was explained in the previous section, various social impacts of high-rise residential buildings for their occupants were identified. A panel of experts, who were chosen purposefully, was also recruited to validate the identified variables for the chosen context. Criteria such as having relevant education and conducting relevant research were deemed for choosing the experts. This type of sampling is considered to be suitable for inviting the right experts [40].

In the second stage, the same panel of experts was interviewed to explore the interrelationships among the social variables. To this purpose, the nominal group technique was used, in which group interviews were conducted in a way that ensured the interviewees addressed issues independently, free from any interference by other participants [41]. That is to say, this method enables participants to have their voices heard and opinions considered by others. While groups of between two and fourteen participants have been used in nominal group research, a maximum of seven has been recommended [42]. 


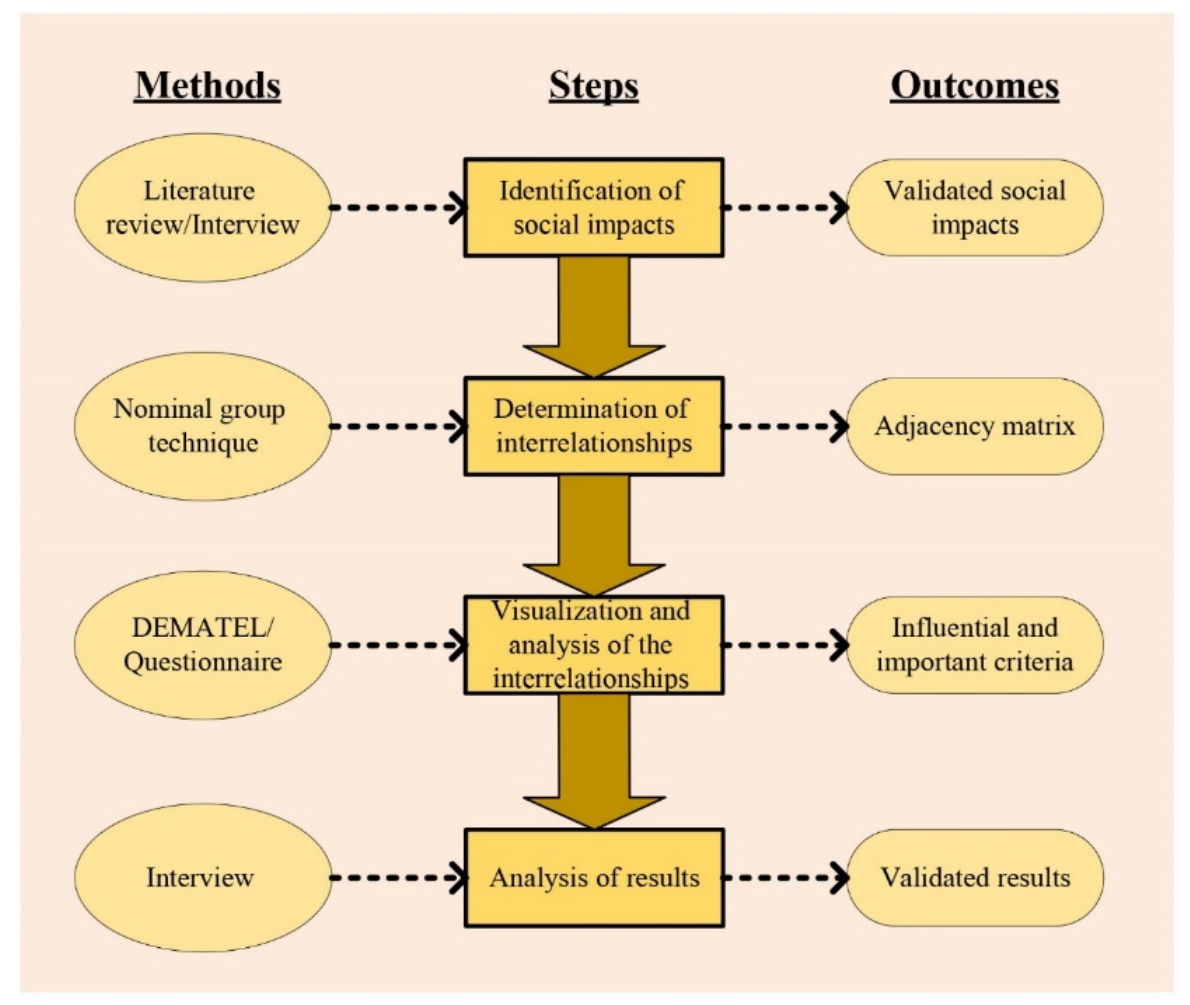

Figure 2. Research process.

In the third stage, by drawing on the experience of 230 residents who were chosen using convenience sampling, the level of influence that each variable exerts on others was determined. A close-ended questionnaire survey, which was designed based on the results of the previous interviews with the panel of experts, was used for this purpose. The collected data were analyzed using the DEMATEL approach to identify the most important as well as influential social variables.

In the fourth stage, in-depth interviews were conducted with seven accessible residents to explain and examine how respondents' personal experiences regarding the social variables matched the results achieved from the questionnaire survey. This type of interview is suitable for deep exploration of the perceptions and experiences of research participants and allows them to explain a situation with their own words [43].

Further information about each stage has been provided below.

\subsection{Data Collection}

To validate the identified social variables and ensure that no significant factor is ignored, interviews were conducted with a panel of seven experts, all of whom had at least fifteen years of experience researching relevant social sciences and public health domains. They all had doctorate degrees from reputable universities, which made them appropriate for the purpose of this study. They were asked to discuss why and how living in high-rise residential buildings can cause the identified social impacts. While they had a chance to add other social impacts, they did not agree upon new factors. They finally reached a consensus that these variables are the most relevant and significant and should be employed for the next stage. Next, through another session, the same respondents were requested to investigate variables' interactions. That is to say, they determined which variable can potentially exert influence on the other variables and which can be impacted on by others. As experts' opinions might differ, the nominal group technique was deployed. This process continued until a consensus on variables' interactions was obtained. The main purpose for adopting this approach was to ensure that the residents would only examine the relations that were previously analyzed by experts and approved to be existing scientifically. According to the final decision of experts regarding variables' 
interactions, a questionnaire was finally designed to be distributed among the residents. A pilot test was also used to ensure that the structure of the questionnaire and designed questions are appropriate. It was intended to ensure that valid data are collated. Based on the achieved feedback, some questions were adjusted to make them less vague and more straightforward.

The questionnaire used in this research was comprised of three sections. In the first section, some general information about the purpose of the research was provided. Additionally, each social impact was described simply and through examples to ensure that all the respondents had the same perception of the social impacts. For instance, vandalism, violence, intimidation, noisy neighbors, abandoned cars, etc., were provided as examples of anti-social behavior, and going to the shops when you are unwell, borrowing money, and giving advice and support in a crisis were supplied as examples of social support. In the second section, the respondents were asked to declare some general information about themselves including age, gender, education, employment status, length of residence, and ownership status. The personal characteristics of respondents are depicted in Table 1. In the last section, they were requested to rate the extent to which they considered a certain variable impacted other variables, on a predetermined scale (i.e., $4=$ the highest impact to $0=$ no impact). To choose respondents to participate in the questionnaires, convenience sampling was used. It was ensured that at least one resident from each identified high-rise building (total of 125 high-rise residential buildings) in the considered district participated in the research. The questionnaire was distributed face-to-face to the residents. For this purpose, first, permission was sought with the management board of the building. Next, residents were visited at home and asked if they were inclined to take part in the questionnaire. The visits were organized at different times of the day, including in the evening, to ensure that employed individuals were also included in the sample. Out of 380 approached residents, $230(60 \%)$ people agreed to participate and completed the questionnaire. The data collection spanned a long period of 10 months, i.e., from November 2019 to September 2020, due to the COVID-19 Pandemic in 2020.

Table 1. Respondents' features.

\begin{tabular}{ccc}
\hline Descriptions & Frequency & Percentage \\
\hline Age & 55 & \\
$18-34$ & 119 & 23.9 \\
$35-54$ & 56 & 51.7 \\
55 and older & & 24.4 \\
Gender & 105 & 45.6 \\
Male & 125 & 54.4 \\
Female & & \\
Education & 30 & 13.0 \\
High school diploma or less & 19 & 8.2 \\
Vocational training/college & 181 & 78.8 \\
University/higher education & & \\
Employment & 156 & 67.9 \\
Employed & 74 & 32.1 \\
Unemployed & & 5.3 \\
Length of residence & 12 & 11.7 \\
Less than 1 year & 27 & 73.0 \\
2 to 5 years & 168 & 10.0 \\
5 to 10 years & 23 & 80.9 \\
More than 10 years & & 19.1 \\
Ownership & 186 &
\end{tabular}

Respondents for the in-depth interviews were approached after gathering and analyzing the distributed questionnaires. Previous literature suggested that to conduct interview 
studies, the minimum sample size is dependent on reaching data saturation [39]. Yin [44] also recommended that for a qualitative study where researchers seek to obtain rich data, two to ten participants would be adequate. In this study, interviews were held with seven occupants to acquire their experiences with their social living environment. Prior to conducting in-depth interviews, the research aims were explained to the residents, and they were given assurance about ethical principles.

\subsection{Data Analysis}

In order to investigate the complex relations among the identified social variables, the DEMATEL approach was used in this research. The DEMATEL method was developed by the Banelle Institute of Geneva for the sciences and human affairs program between 1972 and 1976 [45]. This approach is able to analyze direct and indirect relations among a set of variables, and by providing a simple diagram, which shows how variables are connected to one another, can provide better insight into the core problems of complex systems and assist decisionmakers to plan a roadmap for improvement [46]. In other words, by converting a complex system into a structural causal relationship, this approach can categorize existing criteria into a cause group and an effect group, which makes it easier for decision-makers to decide which criteria to focus on. The end product of the DEMATEL process is an influencerelations map (IRM) that is a visual representation of the interdependencies of the criteria. This approach is widely applied in various fields. For instance, these include the selection of high-performance work systems [47], the selection of the best space for leisure in blighted urban neighborhoods [48], analyzing delays in construction projects [49], developing a strategic management tool for enterprises investing in the sustainable development of coastal areas [50], and analyzing the determinants of smart cities [51]. As this method is successfully employed in diverse areas such as human resource management, project management, and urban planning and design for decision-making purposes, this study therefore adopted this approach.

The essentials of the DEMATEL method are reviewed below [52-54].

1. Suppose $H$ experts and $n$ variables (social variables in this research) are available. Each chosen respondent is requested to clarify a level that reflects the impact of the variable $i$ on the variable $j$. The scale of scores ranged from 0 to 4 that, where 0 indicates no impact and 4 indicates very high impact.

2. The primary direct-relation matrix $D$ is an $n \times n$ matrix that is achieved by pairwise comparisons from the perspective of influences and directions between variables, in which $m_{i j}$ shows the degree to which the variable $D_{i}$ impacts variable $D_{j}$. Accordingly, all principal diagonal elements $m_{i j}$ of matrix $D$ are set to zero.

$$
D=\left[\begin{array}{cccc}
0 & m_{12} & \cdots & m_{1 n} \\
m_{21} & 0 & \cdots & m_{2 n} \\
\vdots & \vdots & \ddots & \vdots \\
m_{n 1} & m_{n 2} & \cdots & 0
\end{array}\right]
$$

Each element of matrix $D$ is the average of scores assigned by each respondent:

3. Let $S=\max _{i}\left(\sum_{j=1}^{n} m_{i j}\right)$ then, the normalized direct-relation matrix $X$ can be achieved via Equation (2):

$$
X=\frac{D}{S}
$$

4. The total-relation matrix $T$ can be calculated using Equation (3), in which $I$ is the identity matrix.

$$
T=\lim _{k \rightarrow \infty}\left(X+X^{2}+\ldots+X^{k}\right)=X(I-X)^{-1}
$$


5. Let $t_{i j}(i, j=1 ; 2 ; \ldots ; n)$ be the elements of the total relation matrix $T$; then, the sum of the rows $\left(R_{i}\right)$ and the sum of the columns $\left(C_{j}\right)$ can be obtained through Equations (4) and (5), respectively:

$$
\begin{aligned}
& R_{i}=\sum_{j=1}^{n} t_{i j},(i=1,2, \ldots, n) \\
& C_{j}=\sum_{i=1}^{n} t_{i j},(j=1,2, \ldots, n)
\end{aligned}
$$

where $C_{i}$ represents the sum of the direct and indirect influence of factor $i$ on other factors, and $R_{j}$ denotes the sum of the direct and indirect influence on factor $j$ by other factors. Using the value of $R-C$, variables could be categorized into a cause group and an effect group, and using the value of $R+C$, the most significant variables could be identified.

The social impacts of living in high-rise residential buildings were analyzed, and their interactions were constructed using the DEMATEL approach. The initial direct-relation matrix depicted in Table 2 was achieved through Equation (1).

Table 2. The initial direct-relations matrix.

\begin{tabular}{cccccccccc}
\hline Criteria & S1 & S2 & S3 & S4 & S5 & S6 & S7 & S8 & S9 \\
\hline S1 & 0.000 & 0.000 & 3.526 & 3.894 & 2.567 & 3.811 & 3.621 & 1.801 & 2.123 \\
S2 & 0.000 & 0.000 & 0.000 & 2.108 & 0.000 & 0.000 & 0.000 & 1.465 & 0.000 \\
S3 & 3.284 & 3.054 & 0.000 & 2.921 & 3.537 & 3.729 & 3.747 & 3.819 & 3.841 \\
S4 & 2.374 & 1.753 & 0.000 & 0.000 & 2.530 & 2.521 & 3.081 & 0.000 & 0.807 \\
S5 & 3.121 & 0.000 & 2.353 & 2.874 & 0.000 & 3.461 & 3.392 & 0.000 & 2.437 \\
S6 & 3.249 & 0.000 & 3.134 & 3.041 & 0.000 & 0.000 & 3.141 & 1.321 & 3.247 \\
S7 & 2.484 & 0.000 & 1.474 & 2.556 & 3.064 & 3.026 & 0.000 & 0.000 & 3.233 \\
S8 & 0.000 & 0.000 & 2.717 & 0.000 & 0.000 & 0.000 & 0.000 & 0.000 & 0.000 \\
S9 & 2.847 & 1.666 & 2.664 & 0.000 & 0.000 & 2.724 & 3.227 & 3.522 & 0.000 \\
\hline
\end{tabular}

Having achieved the initial direct-relation matrix, the value of $S$ was calculated. As the sum of the elements on the third row had the highest value of 27.932, to obtain the normalized matrix (Table 3), all the elements were divided by this value based on Equation (2). After achieving a normalized direct-relation matrix $X$, the total-relation matrix $T$ can be acquired by using Equation (3). This matrix is depicted in Table 4. Using the elements of matrix $T$, the values of $R_{i}$ and $C_{i}$ were also determined, which are shown in Table 5 . As can be seen in this table, based on the values of $R_{i}-C_{i}$ for each criterion, they were also categorized into a cause group and an effect group.

Table 3. The normalized matrix.

\begin{tabular}{cccccccccc}
\hline Criteria & S1 & S2 & S3 & S4 & S5 & S6 & S7 & S8 & S9 \\
\hline S1 & 0.0000 & 0.0000 & 0.1262 & 0.1394 & 0.0919 & 0.1364 & 0.1296 & 0.0645 & 0.0760 \\
S2 & 0.0000 & 0.0000 & 0.0000 & 0.0755 & 0.0000 & 0.0000 & 0.0000 & 0.0524 & 0.0000 \\
S3 & 0.1176 & 0.1093 & 0.0000 & 0.1046 & 0.1266 & 0.1335 & 0.1341 & 0.1367 & 0.1375 \\
S4 & 0.0850 & 0.0628 & 0.0000 & 0.0000 & 0.0906 & 0.0903 & 0.1103 & 0.0000 & 0.0289 \\
S5 & 0.1117 & 0.0000 & 0.0842 & 0.1029 & 0.0000 & 0.1239 & 0.1214 & 0.0000 & 0.0872 \\
S6 & 0.1163 & 0.0000 & 0.1122 & 0.1089 & 0.0000 & 0.0000 & 0.1125 & 0.0473 & 0.1162 \\
S7 & 0.0889 & 0.0000 & 0.0528 & 0.0915 & 0.1097 & 0.1083 & 0.0000 & 0.0000 & 0.1157 \\
S8 & 0.0000 & 0.0000 & 0.0973 & 0.0000 & 0.0000 & 0.0000 & 0.0000 & 0.0000 & 0.0000 \\
S9 & 0.1019 & 0.0596 & 0.0954 & 0.0000 & 0.0000 & 0.0975 & 0.1155 & 0.1261 & 0.0000 \\
\hline
\end{tabular}


Table 4. The total-relation matrix.

\begin{tabular}{cccccccccc}
\hline Criteria & S1 & S2 & S3 & S4 & S5 & S6 & S7 & S8 & S9 \\
\hline S1 & $\mathbf{0 . 1 5 5 3}$ & 0.0565 & $\mathbf{0 . 2 4 5 5}$ & $\mathbf{0 . 2 6 9 5}$ & $\mathbf{0 . 1 9 3 9}$ & $\mathbf{0 . 2 9 1 4}$ & $\mathbf{0 . 2 9 3 5}$ & $\mathbf{0 . 1 5 1 8}$ & $\mathbf{0 . 2 1 4 1}$ \\
S2 & 0.0142 & 0.0072 & 0.0120 & 0.0838 & 0.0123 & 0.0155 & 0.0171 & 0.0574 & 0.0100 \\
S3 & $\mathbf{0 . 2 7 4 6}$ & $\mathbf{0 . 1 5 8 8}$ & $\mathbf{0 . 1 5 3 8}$ & $\mathbf{0 . 2 5 6 2}$ & $\mathbf{0 . 2 2 8 9}$ & $\mathbf{0 . 3 0 4 0}$ & $\mathbf{0 . 3 1 2 8}$ & $\mathbf{0 . 2 3 3 3}$ & $\mathbf{0 . 2 7 8 4}$ \\
S4 & $\mathbf{0 . 1 7 0 1}$ & 0.0842 & 0.0810 & 0.0925 & $\mathbf{0 . 1 4 7 4}$ & $\mathbf{0 . 1 8 4 2}$ & $\mathbf{0 . 2 0 5 2}$ & 0.0495 & 0.1137 \\
S5 & $\mathbf{0 . 2 4 0 4}$ & 0.0478 & $\mathbf{0 . 1 9 4 6}$ & $\mathbf{0 . 2 2 3 7}$ & 0.0965 & $\mathbf{0 . 2 6 4 4}$ & $\mathbf{0 . 2 6 9 0}$ & 0.0835 & $\mathbf{0 . 2 0 9 0}$ \\
S6 & $\mathbf{0 . 2 3 0 8}$ & 0.0499 & $\mathbf{0 . 2 1 1 6}$ & $\mathbf{0 . 2 1 4 5}$ & 0.0946 & 0.1393 & $\mathbf{0 . 2 4 7 2}$ & 0.1283 & $\mathbf{0 . 2 2 2 1}$ \\
S7 & $\mathbf{0 . 2 0 6 7}$ & 0.0425 & $\mathbf{0 . 1 5 6 3}$ & $\mathbf{0 . 1 9 7 2}$ & $\mathbf{0 . 1 8 2 1}$ & $\mathbf{0 . 2 3 4 6}$ & 0.1432 & 0.0755 & $\mathbf{0 . 2 1 8 4}$ \\
S8 & 0.0267 & 0.0155 & 0.1122 & 0.0249 & 0.0223 & 0.0296 & 0.0304 & 0.0227 & 0.0271 \\
S9 & $\mathbf{0 . 1 9 4 5}$ & 0.0927 & $\mathbf{0 . 1 8 8 6}$ & 0.1037 & 0.0754 & $\mathbf{0 . 2 0 1 6}$ & $\mathbf{0 . 2 2 0 8}$ & $\mathbf{0 . 1 9 1 3}$ & 0.0993 \\
\hline
\end{tabular}

Table 5. Degree of total influence of each criterion.

\begin{tabular}{cccccccc}
\hline Criteria & $\boldsymbol{R}_{\boldsymbol{i}}$ & $\boldsymbol{C}_{\boldsymbol{i}}$ & $\boldsymbol{R}_{\boldsymbol{i}}+\boldsymbol{C}_{\boldsymbol{i}}$ & Rank & $\boldsymbol{R}_{\boldsymbol{i}}-\boldsymbol{C}_{\boldsymbol{i}}$ & Rank & Group \\
\hline S1 & 1.8716 & 1.5133 & 3.3849 & 2 & 0.3583 & 3 & Cause \\
S2 & 0.2294 & 0.5550 & 0.7844 & 9 & -0.3257 & 7 & Effect \\
S3 & 2.2007 & 1.3558 & 3.5565 & 1 & 0.8450 & 1 & Cause \\
S4 & 1.1278 & 1.4661 & 2.5939 & 7 & -0.3383 & 8 & Effect \\
S5 & 1.6288 & 1.0531 & 2.6820 & 6 & 0.5757 & 2 & Cause \\
S6 & 1.5383 & 1.6644 & 3.2027 & 3 & -0.1261 & 5 & Effect \\
S7 & 1.4564 & 1.7392 & 3.1956 & 4 & -0.2827 & 6 & Effect \\
S8 & 0.3113 & 0.9933 & 1.3047 & 8 & -0.6820 & 9 & Effect \\
S9 & 1.3680 & 1.3921 & 2.7601 & 5 & -0.0242 & 4 & Effect \\
\hline
\end{tabular}

According to the results, the IRM diagram of the interrelationships was also mapped based on the datasets of $\left(R_{i}-C_{i}, R_{i}+C_{i}\right)$, which is illustrated in Figure 3. Figure 4 also represents the complex causal relations among the criteria. To simplify this figure, first, the average of matrix $T$ elements was calculated, which equaled 0.145 . Then, only the relations between each pair of factors that had a value of more than 0.145 in matrix $T$ were considered and shown as ties. The values of the mentioned relations are shown in bold in Table 4. In this figure, the width of a tie between two factors represents the level of influence that flows between them. Hence, a wider tie is indicative of a more powerful influence that a factor has on another factor. The size of each factor also represents the control that a factor has over the influence passing through it. For instance, in this study, the tie from S3 to S1 is one of the widest, based on the data depicted in Tables 4, S1, and S3, which are the key causes based on the data presented in Table 5 and have the largest size in this figure. 


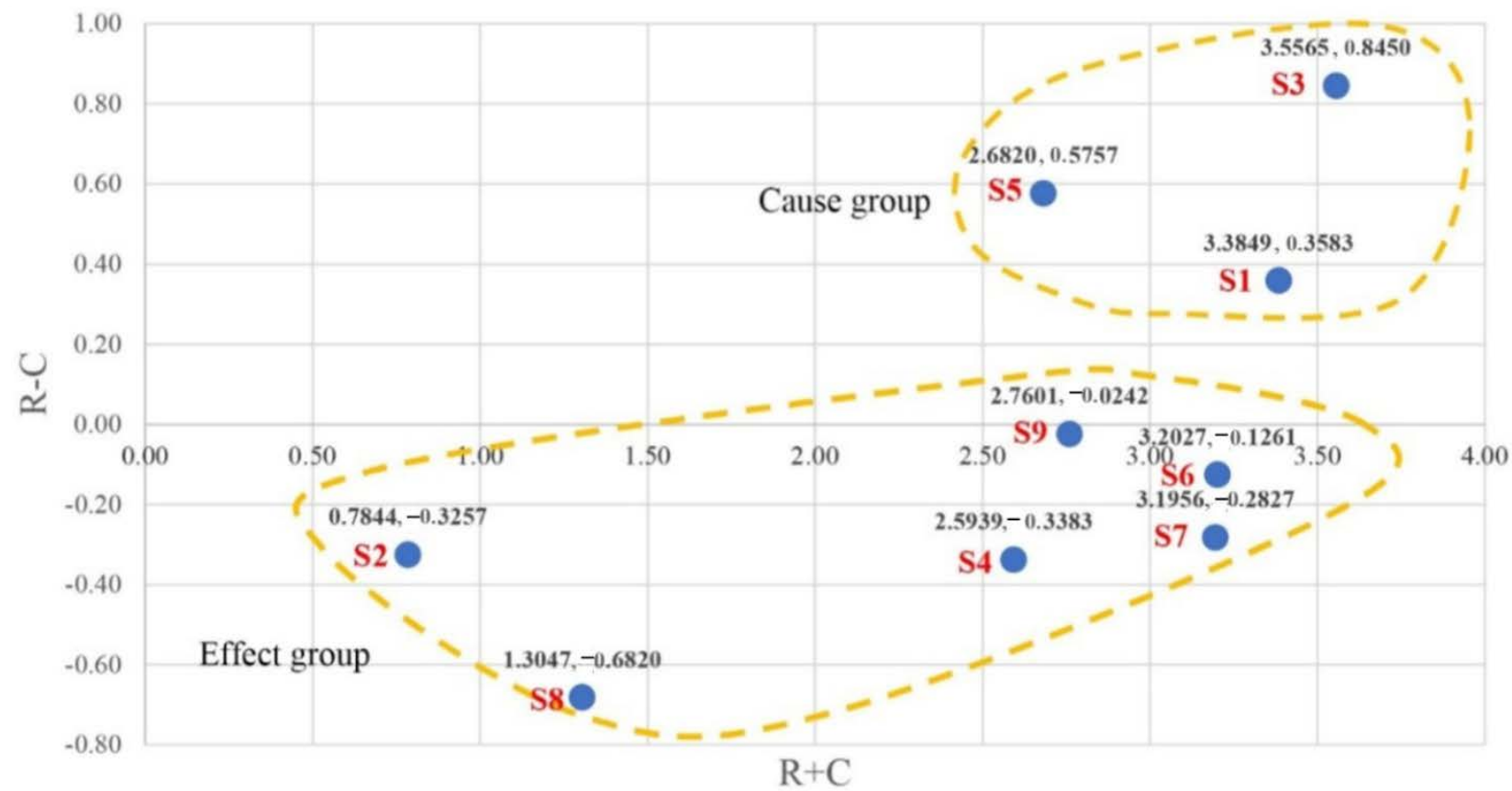

Figure 3. The influence-relations map of the criteria.

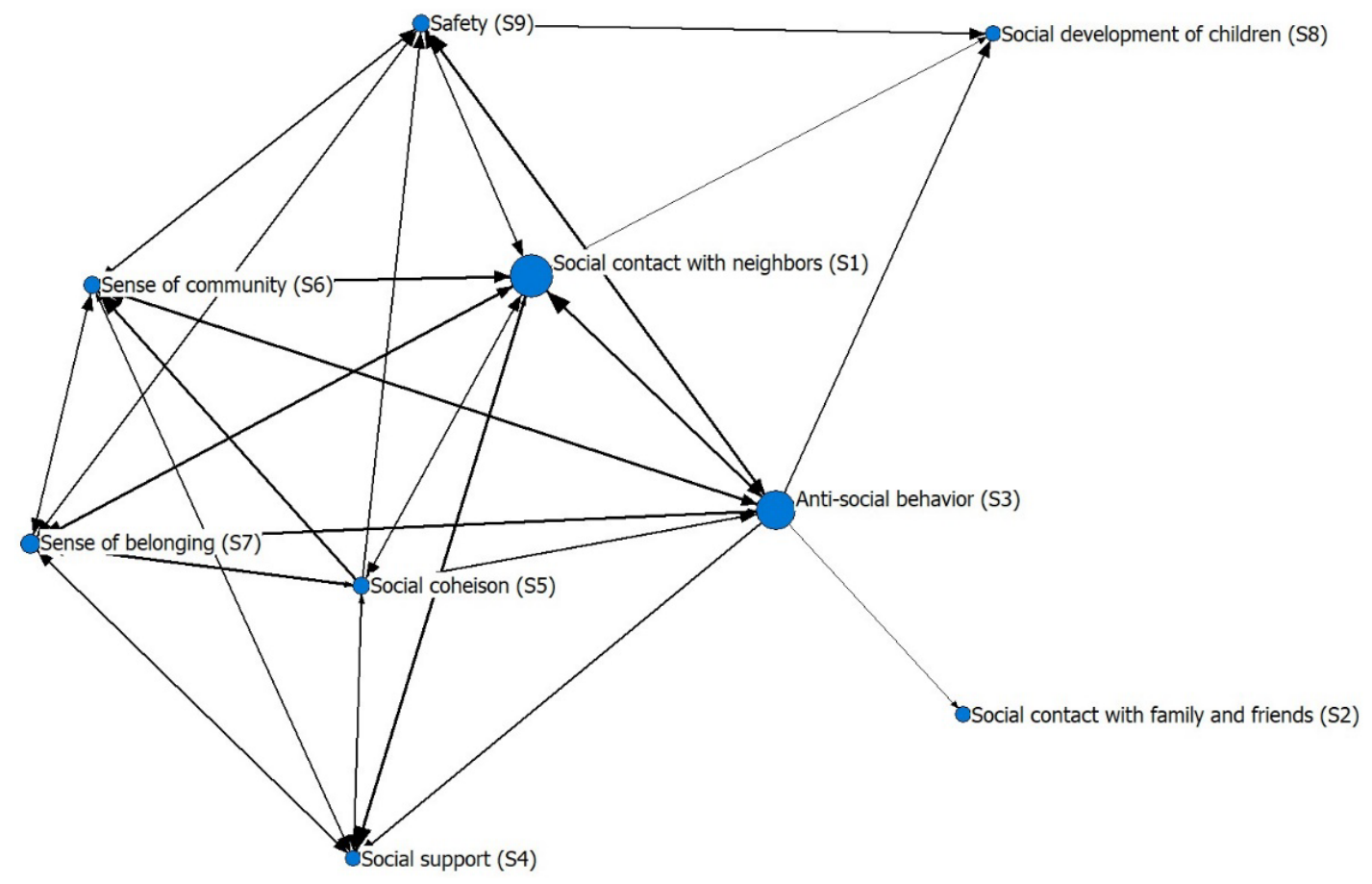

Figure 4. Causal relations map.

\section{Results}

According to the DEMATEL results, the identified factors were arranged based on the degree of importance $\left(R_{i}+C_{i}\right.$ value). A higher value of $\left(R_{i}+C_{i}\right)$ means that the factor has a stronger connection with the other factors and plays a central role [55]. That is to say, $R_{i}+C_{i}$ shows the relative significance of the different affecting factors. As illustrated in Figure 3, "anti-social behavior" had the highest $R_{i}+C_{i}$ value of 3.556. It can therefore be concluded that this factor has the strongest connection with other social impacts resulting from living in high-rise residential buildings. According to the achieved results, three other most significant factors that had strong connections with other factors were "social contact 
with neighbors", "sense of community", and "sense of belonging" with $R_{i}+C_{i}$ values of 3.384, 3.202, and 3.195, respectively. The rest of the factors were arranged as follows: S9 > S5 > S4 > S8 > S2. Looking at the opposite side of Figure 3, it is also clear that "social contact with family and friends" had the weakest connection with other factors and can be regarded as the least important factor.

As shown in Figure 3 and Table 5 , the $R_{i}-C_{i}$ value was also employed to classify the factors into the cause group and effect group. The factors that have a positive value of $R_{i}-C_{i}$ belong to the cause group, and those with a negative value of $R_{i}-C_{i}$ belong to the effect group. The value of $R_{i}-C_{i}$ is also representative of the level of manageability of factors. The factors in the cause group are in fact the root causes that do not experience high influence from other factors, and for this reason, they can be managed more easily. On the contrary, factors belonging to the effect group mainly experience influence from various factors, and they are therefore taxing to handle. According to the results, "social contact with neighbors", "anti-social behavior", and "social cohesion" with positive $R_{i}-$ $C_{i}$ values were classified into the cause group, and the rest of the factors including S2, S4, S5, S6, S7, S8, and S9 with negative $R_{i}-C_{i}$ values were classified into the effect group. Among all the cause group factors, "anti-social behavior" had the maximum value of $R_{i}$ $-C_{i}(0.845)$, which indicates that not only is it the most significant factor, but it is also the key factor that exerts the highest influence on other factors. Similarly, "social contact with neighbors" with the $R_{i}-C_{i}$ value of 0.358 is among the most important and the most influential factors. Although "social cohesion" with an $R_{i}+C_{i}$ value of 2.682 was ranked sixth in terms of importance, with an $R_{i}-C_{i}$ value of 0.575 , it was identified as the second largest root cause, which implies that by being able to trigger other factors, it also deserves attention. On the other side, by looking at the effect group factors, it can be inferred that "sense of community" and "sense of belonging" are the most significant factors that are highly influenced by others. They are followed by "safety", which has an $R_{i}+C_{i}$ value of 2.760 and an $R_{i}-C_{i}$ value of -0.024 and is therefore another principal factor in the effect group factors.

\section{Discussions}

This section reports the findings of qualitative interviews and is accompanied by quotes to illustrate respondents' experiences. Given the vital importance of factors that highly influence others, this part only focuses on three main root causes, which were identified via the DEMATEL technique. The outcomes are compared with the results of the previous literature to validate them, and recommendations are also presented to mitigate the adverse impacts of identified factors.

\subsection{Anti-Social Behavior}

It seems that the causes of this problem for the chosen region mainly lie in the management and cultural issues. The members of the management board must be determined based on consensus among the residents. However, as most of them are loath to participate in the election, managers do not have the power that is expected. Another problem is that they are not adequately supported by national codes, and, for example, if they want to go to the law when someone does not pay monthly charges, they will be involved in a long process that eventually makes them reluctant to proceed. From the cultural point of view, it seems that the residents have already accepted the bad reputation of high-rise buildings, and they are not willing to try to improve the situation.

"... There are some benefits for the managers, and they just accept the responsibility to take advantage of those benefits.... I never saw that they do something effective to stop someone from doing that act again. They just warn them about their acts, but we all know that they are not able to blow the whistle formally against them. . . at the beginning, I was trying to do something. But now when I see that someone does these acts before my very eyes, and does not care, I have become somehow apathetic." 
Previous studies showed that residents of high-rise residential buildings are more likely to be subject to serious anti-social behavior [11]. It is recommended that the management of high-rise residential buildings must ameliorate the degree of intensity and community engagement in order to tackle problems of anti-social behavior [11]. Public policy and managers also have to face the challenge of presenting and promoting a better image of the high-rise, in addition to the physical and social renewal tasks [11]. It is worth mentioning that some researchers also offered design options for solving this problem. For instance, it is argued that providing greater external visibility for high-rise streetscapes and pedestrian-friendly streetscapes could be a deterrent to anti-social behavior [56,57]. Therefore, designers could also contribute to mitigating the adverse effects of this factor.

\subsection{Social Contact with Neighbors}

Living in proximity to each other and having appropriate spaces for social interaction are mentioned as factors that can promote social interactions among the residents [58]. With this fact in mind, it seems that the main reason for the lack of social contact with neighbors in the selected district is the shortage of spaces of this type designed for this purpose. While according to the municipality's codes, designers are meant to design communal areas for these projects, these spaces are not of adequate quality and most residents are reluctant to spend time there. As a result, they prefer public spaces in the neighborhood, which might not be even within the walking distance of their apartments.

"While I have been living here for 6 years, I am in contact with few neighbors. Whenever I want to use the elevator, it seems that someone new is waiting there. .. Why should I spend time in an enclosed area which does not have any facilities and any view of the greenery areas? It is far from relaxing and makes me depressed. They are only used for regular owners' association meetings which are held once a year, and not all the residents participate. ... I would rather while away with my family in a park. If there was a similar, even small area in the building's site, we would not have to commute this way."

There is a broad consensus among scholars that social contacts with neighbors can enhance social cohesion and the sense of community $[59,60]$. Social interaction provides the opportunity for the residents to gain more information about other neighbors and the social structure of the community, which in turn, can help to develop neighborhood communities [61]. This builds friendship patterns and social connections and creates common rules of community [62]. Previous studies showed that in this case, designers can help to solve the problem. Kalantari and Shepley [19] suggested that providing vibrant communal spaces and lobbies can stimulate community activities and interaction in residential high-rises. Huang [63] suggested that enclosed central courtyards in which visual centerpieces such as fountains and sculptures are provided can also guarantee more social interaction. Overall, the diversity, quality, accessibility, and visibility of communal spaces are the predominant design variables, which designers should focus on to enhance social interaction [58].

\subsection{Social Cohesion}

It seems that the main reason for the lack of social cohesion in the chosen region is selling the apartments at a far lower price when they are at the construction stage. It is self-evident that the construction of high-rise buildings demands huge financial resources, and due to the volatile economic conditions of the targeted country, it seems that most builders are unable to plan their cash flow, and in order to compensate the required budget, they resort to preselling the apartments. The buyers of these apartments are mainly people with different cultures and background that have just migrated to Tehran from other cities to find a job and make a living. People buying the completed apartments, on the contrary, are supposed to pay the total cost when signing the contract. These people have a better financial status and have lived in Tehran for years. They are also mainly from upper social levels and are familiar with the code of conduct existing for living in apartments. As these 
groups are from different social levels and have different cultures, they cannot deal with each other easily, which leads to a lack of social cohesion in this district.

"Due to the economic condition, builders of this district are not able to completely finance the project, and for this reason, as I know lion's share of my neighbors purchased their apartments when they were at the construction stage, with much lower price, and have to pay the rest via multiple installments. I personally respect these people as they are my neighbors as well. But having lived here for close on 8 years, I feel that they are not matched with other neighbors, and it seems difficult for them to abide by even the simplest codes that others agreed upon.... It is frustrating to see that they still put their shoes behind the door in the corridor and do not take part in regular owners' association meetings."

Kearns et al. [11] argued that residents of high-rise flats are about twice as likely as others to experience poor cohesion, notably those living in lower floors. Previous studies also revealed that semi-public spaces intrinsic to high-rise residential buildings and situated on the ground floor can potentially exacerbate social cohesion for people living on lower floors [20]. It was also revealed that the quality of communal spaces such as corridors and staircases can give rise to the level of social cohesion as most social ties form in these areas [64]. Considering the targeted region it seems that the situation is out of designers' control, and the onus is on the authorities to facilitate loans from local banks for builders of these projects to prevent the consequent social impacts of presales.

\section{Conclusions}

Growing demand for accommodation within the cities, which is caused by a dramatic demographic change across the globe, has made high-rise residential buildings a popular built form as they can make the most of vertical space. Living in these buildings, however, is associated with various social impacts such as a lack of social contact with family and friends, lack of social contact with neighbors, anti-social behavior, social support deficiency, social cohesion deficiency, shortages of a sense of belonging, shortages of a sense of community, impaired social development of children, and safety issues. While some of these impacts have been identified and discussed by previous research, no attention has been paid to how these social impacts are connected to one another. To bridge this gap, this study used a mixed-method approach. First, the above-mentioned social impacts were identified through the literature review and verified by a panel of experts. By conducting interviews with the experts the possible relations among them were then determined. Next, by drawing on the experience of 230 residents who were chosen from high-rise residential buildings of District 22 of Tehran, the level of influence that each variable exerts on others was determined. The DEMATEL method was used to analyze the collected data and to identify the most critical and influencing factors. Finally, interviews were conducted with a group of residents to validate and discuss the achieved results. The findings revealed that "social contact with neighbors", "anti-social behavior", and "social cohesion" are the main root causes of the problem. It was also unveiled that while "sense of community" and "sense of belonging" mainly receive influence from other factors, they play a critical role in the network of factors, and as a result, deserve to be paid more attention. It was discussed that the onus is on a group of people, including designers, urban planners, policymakers, and building managers to take measures to mitigate the social impacts of living in high-rise buildings and to improve occupants' social wellbeing.

\subsection{Theorethical Implications}

This study has numerous theoretical implications. The first one is that this study provides academia with a list of major social impacts of living in high-rise residential buildings experienced in the Iranian context. This forms a basis for future studies to boost the robustness and comprehensiveness of the list for application in other developing countries. The second one is that it used a powerful and robust method, namely the DEMATEL method, to show how various social impacts arising from living in high-rise buildings interact with one another, and the model was validated by a group of qualified 
experts. This provides better insight into the complex interrelationships among these factors. Third, the proposed approach will help to compare and benchmark the results in other types of high-rise buildings and in other contexts. Finally, the outcomes contribute to knowledge on how to use advanced approaches to develop models and conduct an evaluation on abstract subjects.

\subsection{Managerial Implications}

Current demands of sustainability oblige designers and urban planners to give equal primacy to the mental health and social wellbeing of high-rise residential buildings' occupants along with their level of comfort and environmental satisfaction. The process of integrating social wellbeing with the traditional urban and building design strategies could be efficient if both of these concepts are considered concomitantly. This study offers a framework to address this challenge. That is to say, the first managerial implication of this work is that the developed model could be a benchmark for decision-makers to focus on the most important and influential factors in order to find diverse solutions that have the highest effectiveness and efficiency, rather than individually implementing the strategies, which might be more time-consuming and demand trial and tribulations. In this way, decision-makers can gain insight into how their adopted strategies can mitigate social impacts and enhance the social wellbeing of residents. The second managerial implication of this study emerges from the fact that the components of the developed model are identified and corroborated by the literature review, and the interrelationships among them are also validated by a panel of reliable experts irrespective of the context. Therefore, by collecting relevant data, decision-makers can use the proposed model to identify the major social impacts in other contexts and devise proportionate strategies for them as well.

\subsection{Limitations and Future Research}

The limitations of this study are as follows. First, it should be acknowledged that this research investigated the interrelationships among the variables irrespective of factors that can affect respondents' attitudes. Future research should, therefore, consider moderators and mediators (e.g., personal characteristics, buildings' characteristics, and social control) to evaluate how urban design and architectural solutions can improve social well-being. Second, it should be noted that due to the cultural differences, the results and recommended solutions might not be necessarily generalizable to other contexts, whereas the developed model could be a benchmark for researchers to examine this problem in other settings. Finally, this study used crisp values to assess the degree of influence among factors, which neglects the possible uncertainty in the opinions. Therefore, fuzzy DEMATEL is a more suitable option to be adopted in future research.

Author Contributions: Conceptualization, N.K.A.D., S.S. and A.B.; Data curation, N.K.A.D., R.A., D.T., M.K. and A.B.; Formal analysis, S.S.; Investigation, N.K.A.D., R.A., D.T., M.K., S.S. and A.B.; Methodology, R.A., D.T., M.K., S.S. and A.B.; Project administration, S.S. and A.B.; Software, N.K.A.D.; Writing—original draft, S.S.; Writing—review \& editing, N.K.A.D., R.A., D.T., M.K. and A.B. All authors have read and agreed to the published version of the manuscript.

Funding: This research received no external funding.

Institutional Review Board Statement: Not applicable.

Informed Consent Statement: Not applicable.

Data Availability Statement: Not applicable.

Acknowledgments: Not applicable.

Conflicts of Interest: The authors declare no conflict of interest. 


\section{References}

1. Myers, D. Construction Economics, A New Approach; Routledge: London, UK, 2013.

2. Shoar, S.; Payan, S. A qualitative system dynamics approach to modeling the causes and effects of design deficiencies in construction projects. J. Facil. Manag. 2021, in press. [CrossRef]

3. Shoar, S.; Nazari, A. An Optimization Framework for Risk Response Actions Selection Using Hybrid ACO and FTOPSIS. Sci. Iran. 2019, 26, 1763-1777. [CrossRef]

4. Zaini, A.A.; Sofwan, N.M. Modelling risk factors and challenges with the implementation of risk management in high-rise building construction. Malays. Constr. Res. J. 2020, 32, 59-70.

5. Farouk, A. High Rise Buildings and How They Affect Countries Progression. E-iataorC Leader 2011 2011, 1-14. Available online: https:/ / www.g-casa.com/conferences/zagreb/papers/Akram1-HighRise.pdf (accessed on 10 October 2020).

6. Eichner, M.; Ivanova, Z. Socioecological Aspects of High-rise Construction. In Proceedings of the E3S Web of Conferences, Polanica-Zdrój, Poland, 16-18 April 2018; Volume 33.

7. Kloft, E. High-rise Manual, Typology and Design, Construction and Technology; Birkhäuser: Basel, Switzerland, 2003.

8. Urban Strategies, Tall Building Design Guidelines; Urban Strategies: Toronto, ON, Canada, 2013.

9. Perera, B.A.K.S.; Samarakkody, A.L.; Nandasena, S.R. Managing financial and economic risks associated with high-rise apartment building construction in Sri Lanka. J. Financ. Manag. Prop. Constr. 2020, 25, 143-162. [CrossRef]

10. Li, R.Y.M.; Chau, K.W.; Zeng, F.F. Ranking of risks for existing and new building works. Sustainability 2019, 11, 2863. [CrossRef]

11. Kearns, A.; Whitley, E.; Mason, P.; Bond, L. "Living the High Life"? Residential, Social and Psychosocial Outcomes for High-Rise Occupants in a Deprived Context. Hous. Stud. 2012, 27, 97-126. [CrossRef]

12. World Health Organization Global Health Observatory (GHO) Data. Available online: http://www.who.int/gho/urban_health/ en/ (accessed on 14 August 2019).

13. Doucet, B. Rich Cities with Poor People: Waterfront Regeneration in the Netherlands and Scotland; Utrecht University, Royal Dutch Geographical Society: Utrecht, The Netherlands, 2010; p. 391.

14. Al-Kodmany, K. The sustainability of tall building developments: A conceptual framework. Buildings 2018, 8, 7. [CrossRef]

15. Santoso, D.S.; Ogunlana, S.O.; Minato, T. Assessment of risks in high rise building construction in Jakarta. Eng. Constr. Archit. Manag. 2003, 10, 43-55. [CrossRef]

16. Alexander, C.; Ishikawa, S.; Silverstein, M. A Pattern Language: Towns, Buildings, Construction (Cess Center for Environmental structure Series); Oxford University Press: New York, NY, USA, 1977; p. 1171.

17. Graham, L.T.; Parkinson, T.; Schiavon, S. Lessons learned from 20 years of CBE's occupant surveys. Build. Cities 2021, 2, 166-184. [CrossRef]

18. Wang, N.; Phelan, P.E.; Harris, C.; Langevin, J.; Nelson, B.; Sawyer, K. Past visions, current trends, and future context: A review of building energy, carbon, and sustainability. Renew. Sustain. Energy Rev. 2018, 82, 976-993. [CrossRef]

19. Kalantari, S.; Shepley, M. Psychological and social impacts of high-rise buildings: A review of the post-occupancy evaluation literature. Hous. Stud. 2021, 36, 1147-1176. [CrossRef]

20. Barros, P.; Ng Fat, L.; Garcia, L.M.T.; Slovic, A.D.; Thomopoulos, N.; de Sá, T.H.; Morais, P.; Mindell, J.S. Social consequences and mental health outcomes of living in high-rise residential buildings and the influence of planning, urban design and architectural decisions: A systematic review. Cities 2019, 93, 263-272. [CrossRef]

21. Tehran Municipality Statistical Yearbook of Tehran. Available online: http://tmicto.tehran.ir/Portals/0/Document/Amarname/ NEWPDF/AmarShahr/92-TehranStatisticalYearBook.pdf (accessed on 10 October 2020).

22. Vafai, H.; Parivar, P.; Sehat Kashani, S.; Farshforoush Imani, A.; Vakili, F.; Ahmadi, G. Environmental impact analysis of high-rise buildings for resilient urban development. Sci. Iran. 2020, 27, 1843-1857. [CrossRef]

23. Brueckner, J.K.; Lall, S.V. Chapter 21-Cities in Developing Countries: Fueled by Rural-Urban Migration, Lacking in Tenure Security, and Short of Affordable Housing. In Handbook of Regional and Urban Economics; Duranton, G., Henderson, J.V., Strange, W.C., Eds.; Elsevier: Amsterdam, The Netherland, 2015; Volume 5, pp. 1399-1455. ISBN 1574-0080.

24. Brent Council. London Borough of Brent Core Strategy: Tall Building; Brent Council: London, UK, 2005.

25. Sotiropoulou, A.; Karagiannis, I.; Vougioukas, E.; Ballis, A.; Bouki, A. Measurements and prediction of road traffic noise along high-rise building facades in Athens. Noise Mapp. 2020, 7, 1-13. [CrossRef]

26. Sotiropoulou, A.G.; Karalekas, F.; Charemis, C. Subjective evaluation of urban noise in Athens; Multi-dimensional description of evaluations. In Proceedings of the Institute of Acoustics, Oxford, UK, 18-19 October 2005; Volume 27.

27. Chile, L.M.; Black, X.M.; Neill, C. Experience and expression of social isolation by inner-city high-rise residents. Hous. Care Support 2014, 17, 151-166. [CrossRef]

28. Chatterjee, M. A study on loneliness and social interaction pattern among the high rise dwellers of Kolkata city. Res. J. Soc. Sci. 2018, 9, 26-32.

29. Gibson, M.; Thomson, H.; Kearns, A.; Petticrew, M. Understanding the psychosocial impacts of housing type: Qualitative evidence from a housing and regeneration intervention. Hous. Stud. 2011, 26, 555-573. [CrossRef]

30. Ghosh, S. Everyday Lives in Vertical Neighbourhoods: Exploring Bangladeshi Residential Spaces in Toronto's Inner Suburbs. Int. J. Urban Reg. Res. 2014, 38, 2008-2024. [CrossRef]

31. Husaini, B.A.; Moore, S.T.; Castor, R.S. Social and psychological well-being of black elderly living in high-rises for the elderly. J. Gerontol. Soc. Work 1991, 16, 57-78. [CrossRef] 
32. Korte, C.; Huismans, S. Sources of assistance among residents of a Dutch high-rise development. Am. J. Community Psychol. 1983, 11, 751-755. [CrossRef]

33. Kearns, A.; Whitley, E.; Tannahill, C.; Ellaway, A. "Lonesome town"? Is loneliness associated with the residential environment, including housing and neighborhood factors? J. Community Psychol. 2015, 43, 849-867. [CrossRef]

34. Kitchen, P.; Williams, A.; Chowhan, J. Sense of Community Belonging and Health in Canada: A Regional Analysis. Soc. Indic. Res. 2012, 107, 103-126. [CrossRef]

35. Saegart, S. Environments and children's mental health: Residential density and low income children. In Handbook of Psychology and Health; Baum, A., Singer, J.E., Eds.; Erlbaum: Hillsdale, NJ, USA, 1982; pp. 247-271.

36. Wisdom, J.; Creswell, J.W. Mixed Methods: Integrating Quantitative and Qualitative Data Collection and Analysis While Studying Patient-Centered Medical Home Models; Agency for Healthcare Reseach and Quality: Rockville, MD, USA, 2013; pp. 1-5.

37. Oliver-Hoyo, M.; Allen, D. The use of triangulation methods in qualitative educational research. J. Coll. Sci. Teach. 2006, 35, $42-47$.

38. Li, R.Y.M. Generation X and Y's demand for homeownership in Hong Kong. Pac. Rim Prop. Res. J. 2015, 21, 15-36. [CrossRef]

39. Nguyen, L.; van den Berg, P.; Kemperman, A.; Mohammadi, M. Where do people interact in high-rise apartment buildings? Exploring the influence of personal and neighborhood characteristics. Int. J. Environ. Res. Public Health 2020, 17, 4619. [CrossRef]

40. Rowley, J. Designing and using research questionnaires. Manag. Res. Rev. 2014, 37, 308-330. [CrossRef]

41. Janes, F.R. Interpretive structural modelling: A methodology for structuring complex issues. Trans. Inst. Meas. Control 1988, 10, 145-154. [CrossRef]

42. McMillan, S.S.; Kelly, F.; Sav, A.; Kendall, E.; King, M.A.; Whitty, J.A.; Wheeler, A.J. Using the Nominal Group Technique: How to analyse across multiple groups. Health Serv. Outcomes Res. Methodol. 2014, 14, 92-108. [CrossRef]

43. Kim, J.; Yoo, S. Perceived health problems of young single-person households in housing poverty living in Seoul, South Korea: A qualitative study. Int. J. Environ. Res. Public Health 2021, 18, 1067. [CrossRef]

44. Yin, R.K. Case Study Research: Design and Methods; Sage: Thousand Oaks, CA, USA, 1994.

45. Gabus, A.; Fontela, E. Perceptions of the World Problematique: Communication Procedure, Communicating with Those Bearing Collective Responsibility; Battelle Geneva Research Centre: Geneva, Switzerland, 1972.

46. Chiu, C.J.; Hu, J.C.; Lo, Y.H.; Chang, E.Y. Health promotion and disease prevention interventions for the elderly: A scoping review from 2015-2019. Int. J. Environ. Res. Public Health 2020, 17, 5335. [CrossRef]

47. Estiri, M.; Dahooie, J.H.; Vanaki, A.S.; Banaitis, A.; Binkytè-Vèlienè, A. A multi-attribute framework for the selection of highperformance work systems: The hybrid DEMATEL-MABAC model. Econ. Res.-Ekon. Istraz. 2021, 34, 970-997. [CrossRef]

48. Pourahmad, A.; Hosseini, A.; Banaitis, A.; Nasiri, H.; Banaitienė, N.; Tzeng, G.H. Combination of fuzzy-AHP and DEMATELANP with GIS in a new hybrid MCDM model used for the selection of the best space for leisure in a blighted urban site. Technol. Econ. Dev. Econ. 2015, 21, 773-796. [CrossRef]

49. Parchami Jalal, M.; Shoar, S. A hybrid SD-DEMATEL approach to develop a delay model for construction projects. Eng. Constr. Archit. Manag. 2017, 24, 629-651. [CrossRef]

50. Huynh, T.T.M.; Pham, A.D.; Le-Hoai, L. Building a strategic performance management model for enterprises investing to coastal urban projects toward sustainability. Int. J. Strateg. Prop. Manag. 2021, 25, 127-145. [CrossRef]

51. Braga, I.F.B.; Ferreira, F.A.F.; Ferreira, J.J.M.; Correia, R.J.C.; Pereira, L.F.; Falcão, P.F. A DEMATEL analysis of smart city determinants. Technol. Soc. 2021, 66, 101687. [CrossRef]

52. Wang, W.C.; Lin, Y.H.; Lin, C.L.; Chung, C.H.; Lee, M.T. DEMATEL-based model to improve the performance in a matrix organization. Expert Syst. Appl. 2012, 39, 4978-4986. [CrossRef]

53. Parchami Jalal, M.; Shoar, S. A hybrid framework to model factors affecting construction labour productivity: Case study of Iran. J. Financ. Manag. Prop. Constr. 2019, 24, 630-654. [CrossRef]

54. Lin, S.H.; Hsu, C.C.; Zhong, T.; He, X.; Li, J.H.; Tzeng, G.H.; Hsieh, J.C. Exploring location determinants of asia's unique beverage shops based on a hybrid madm model. Int. J. Strateg. Prop. Manag. 2021, 25, 291-315. [CrossRef]

55. Li, C.W.; Tzeng, G.H. Identification of a threshold value for the DEMATEL method using the maximum mean de-entropy algorithm to find critical services provided by a semiconductor intellectual property mall. Expert Syst. Appl. 2009, 36, 9891-9898. [CrossRef]

56. Asgarzadeh, M.; Koga, T.; Hirate, K.; Farvid, M.; Lusk, A. Investigating oppressiveness and spaciousness in relation to building, trees, sky and ground surface: A study in Tokyo. Landsc. Urban Plan. 2014, 131, 36-41. [CrossRef]

57. Jung, E.; Lee, J.; Kim, K. The relationship between pedestrian environments and sense of community in apartment complexes in Seoul, Korea. J. Asian Archit. Build. Eng. 2015, 14, 411-418. [CrossRef]

58. Williams, J. Designing neighbourhoods for social interaction: The case of cohousing. J. Urban Des. 2005, 10, 195-227. [CrossRef]

59. Reid, S. Exploring social interactions and sense of community in multi-owned properties. Int. J. Hous. Mark. Anal. 2015, 8, 436-450. [CrossRef]

60. Lewicka, M. What makes neighborhood different from home and city? Effects of place scale on place attachment. J. Environ. Psychol. 2010, 30, 35-51. [CrossRef]

61. Grannis, R. From the Ground Up: Translating Geography into Community through Neighbor Networks; Princeton University Press: Princeton, NJ, USA, 2009; pp. 1-242.

62. Pretty, J.; Ward, H. Social capital and the environment. World Dev. 2001, 29, 209-227. [CrossRef] 
63. Huang, S.C.L. A study of outdoor interactional spaces in high-rise housing. Landsc. Urban Plan. 2006, 78, 193-204. [CrossRef]

64. Pojani, D.; Buka, M. From camaraderie to detachment: The effect of changing built environment forms on neighborhood relations in a post-communist context. Cities 2015, 49, 66-75. [CrossRef] 